This copy is author's original pre-print version and may slightly differ from the official published version.

\author{
Full citation: \\ Mottonen, M., Belt, P., Harkonen, J. and Lin, B. (2009) 'Managing requirements in ICT companies', Business \\ Process Management Journal, Vol. 15, No. 6, pp. 968-989.
}

DOI: http://dx.doi.org/10.1108/14637150911003810

\title{
Managing requirements in ICT companies
}

\begin{abstract}
Purpose - The purpose of this study is to provide new ideas for improving requirements management in the information and communications technology (ICT) sector. Requirements management has become a challenge for new product development (NPD) as products are getting increasingly complicated and customer segments more fragmented.

Design/methodology/approach - In this research a qualitative interview study was carried out in the ICT sector to clarify the current challenges in requirements management. The results of the interview study were analysed using a benchmark from the automotive industry. The benchmark was chosen as the automotive industry is a developed business sector that has streamlined its business processes, including its requirements management.

Findings - This study shows how ICT can benefit from the experience of the car industry on issues, such as, managing customer needs throughout the NPD process, overflow of data, and communicating requirements with suppliers.

Research limitations/implications - Using another sector as a benchmark is not a straightforward process and results cannot be directly copied. Fresh ideas are, however, obtainable when a well developed benchmark is used and results are applied flexibly. Deeper analysis on individual areas indentified in this study might be interesting topics for further study.

Practical implications - This study showed that the managers in the ICT sector should pay more attention on their requirements management and serving the needs of internal customers. The requirements management of the Japanese automotive industry is a potential source for improvement initiatives.

Originality/value - This study provides new perspectives for the requirements management of the ICT sector by benchmarking the Japanese automotive industry.
\end{abstract}

Keywords requirements management; product development; product design; business process; ICT; automotive industry

Paper type Research paper

\section{Introduction}

The information and communications technology (ICT) industry has expanded rapidly during the last decades, and the rate of new product launches has significantly increased. Companies need to create products that fulfil the needs of their customers in order to succeed in tough global competition. Severe competition and resulting price erosion requires them to cut costs and shorten development times. Competent new product development (NPD) is therefore essential (Nonaka and Takeuchi, 1995; Pisano and Wheelwright 1995; Gupta et al., 2007; Zhang, 2008).

Requirements engineering (RE) is concerned with analysing and documenting requirements (Thayer and Thayer 1997). In other words, RE means that requirements for a system are defined, 
managed and tested systematically. The purpose of RE is to ensure that product development builds a system that satisfies customer and user needs (Kauppinen et al. 2004). Kotonya and Sommerville (1998) define a RE process as a structured set of activities that are followed to derive, validate, and maintain a product requirements document. Requirements management (RM) is the process of understanding and controlling changes to requirements (Sommerville, 2004). The more complex and abstract a product is, the more vital RE \& RM become for successful NPD. This is especially highlighted for software, but is also important for embedded systems containing both hardware and software.

In the ICT sector products are getting more complicated and customer segments increasingly fragmented, making requirements engineering challenging. The literature estimates RE, including testing, to take 30 to 80 percent of the entire costs in high-technology product development (e.g. Engel \& Last, 2007; Gilb, 2005; Perttula, 2007; Belt et al., 2008; Andersson and Runeson, 2002). Product requirements are determined by standards, technical constraints, and especially by customers. The amount or requirements is vast and the number of stakeholders setting them is high. Therefore, defining and agreeing product requirements can be difficult, causing specifications to contain ambiguities (e.g. Kerr et al., 2006; Engelbrektsson and Soderman, 2004; Kim et al., 2004). Requirements are typically non-stabile and do change even during development projects (Weber and Weisbrod, 2003). Mastering the requirements, and their prioritisation, is seen as one of the cornerstones of successful product management, and therefore it is vital to have a clear focus on the major requirements, but most importantly to drive according to the customers' business case in order to deliver value (Ebert, 2007; Jiang et al., 2008). As a consequence, requirements management has become a bottleneck for product development.

The automotive industry has been a large volume, mature and competitive business sector that has streamlined its business processes to a high level. Their requirements management has developed to meet customer needs and efficiency demands simultaneously. Especially, the Japanese car industry has been successful in its sector and is effective also in managing requirements (e.g. Morgan and Liker, 2006), making their example especially interesting for this study.

The business volume of the ICT sector has recently experienced a fast growth, and the management of requirements has become a major disturbing factor for its product development. It is rational for ICT to benchmark the automotive sector for gaining new perspectives and for tackling this challenge. Morgan and Liker, (2006) have analysed the Japanese automotive industry, Toyota in particular. Their three-stage socio-technical NPD model, covering processes, people, and technological issues, is used as a benchmarking tool in this study. This research analyses how ICT companies can improve their requirements management.

The objective of this study can be summarised into the following research questions:

RQ1. To what extent are the principles of the benchmarked three-stage socio-technical model utilised in the requirements management of the ICT industry?

RQ2. What can the ICT companies learn from the Japanese automotive industry for addressing the challenges of their requirements management?

\section{Literature review}

\subsection{Managing requirements}

Traditionally, requirements for products are set by customers, standards and technical constraints (e.g. Darabi et al., 2005). In modern ICT, specifications must not only acknowledge customers, but also other stakeholders, such as business requirements, manufacturing and supply chain (Jiao and Chen, 2006). Requirements can be divided into functional and non-functional ones. Functional requirements describe what a product should do, while non-functional requirements do not have direct influence on a product. Non-functional requirements can be divided into product requirements (e.g. 
reliability), organisational requirements (e.g. manufacturing and supply chain), and external requirements (e.g. legislation and standards). (Sommerville, 2004; Lauesen, 2002). Figure 1 illustrates the NPD process from the requirements viewpoint. Requirements guide the development process; however, different types of changes occur during projects, making iterations necessary (e.g. Weber and Weisbrod 2003). During the process, company management requires understanding over the state of meeting these requirements.

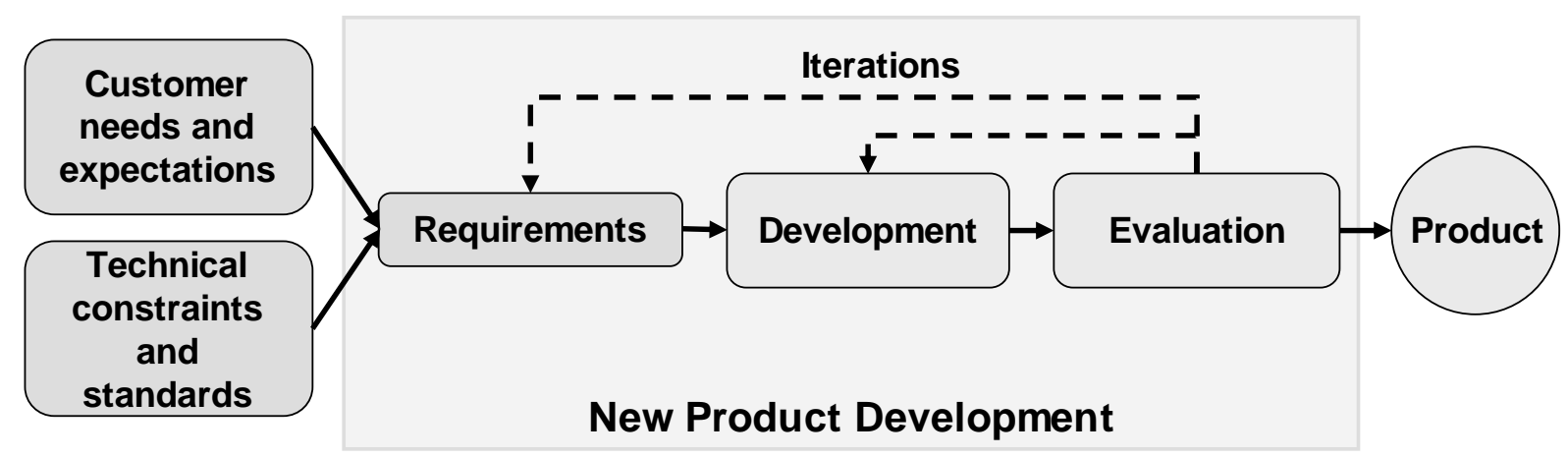

Figure 1. NPD process from the requirements viewpoint

$\mathrm{RE}$ can be seen as a process comprising of four sub-processes:

1. feasibility study

2. elicitation and analysis

3. specification

4. validation

Feasibility study is needed to clarify whether a product under development will be useful for business. Elicitation and analysis concentrate on discovering and indentifying requirements. In the specification process these requirements are converted into a form that is intelligible to product development personnel. Finally, validation checks requirements to confirm that the product complies with customers' wishes. (Sommerville, 2004). In practice, requirements change during product development, as the understanding of the people involved enhances, and customers' requirements change. The fundamental reason for changing requirements lies in problems being too complex to be properly described in the very beginning. Consequently, the RE process is not straightforward, but rather an iterative circle, see Figure 2. Individual requirements that were originally in different formats, are added, refined or removed by negotiations, discussions and clarifications (Kerr et al., 2006). Different types of product plans, sketches, simulations and physical representations can act as tools for communication (Wheelwright and Clark 1994; Ulrich and Eppinger 1995). The process of managing these changing requirements is typically called requirements management (Oberg et al., 1998; Dorfman and Thayer, 1997).
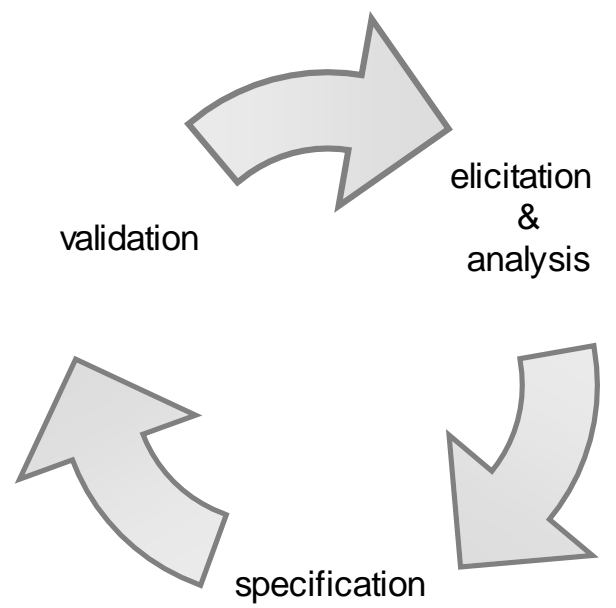


\section{Figure 2. Iterative circle of requirements engineering process}

Managing relevant information is seen to have implications on new product performance (Rui et al., 2008). Companies do not necessarily have experienced requirements engineers at their service, yet hundreds of methods have been constructed to address the problem of acquiring, analysing, and communicating requirements (Fricker et al., 2006; Caputo and Pelagagge, 2008). Cheng and Atlee (2007) have extensively mapped current state-of-the-art of RE, including methodologies, techniques and tools. These methods include, word-processor templates, informal stakeholder interviews, unified modelling language, different commercial web-based and desktop tools (Larsen et al., 2008; INCOSE, 2008; Kamara et al., 2000; Fricker et al., 2006; Misra et al., 2008; Briand et al., 2006).

In modern ICT, especially in large companies, it is typical that new product development occurs in a multi-site, multi-cultural, multi-product environment. Defining and agreeing product requirements is especially important when the design activities, and production, are dispersed. Damian and Zowghi (2003) have indentified RE challenges in multi-site software development: inadequate communication, knowledge management, cultural diversity, time difference. Birk and Heller (2007) have highlighted challenges relating to many product variants, long product life-cycle, many different stakeholders, change management, tool support, and prioritisation of requirements. Jiao and Chen (2006) on their part emphasise the following aspects as challenges in modern ICT industry: customer requirements are often qualitative and fuzzy, different stakeholders use different terminology, and requirements are often poorly understood and expressed in abstract, fuzzy and conceptual terms. In addition, converting customer requirements into product specifications is challenging, especially in early NPD (Jiao and Chen, 2006). Identifying and communicating customer needs and expectations into requirements have been emphasised as a challenge for product development (Engelbrektsson and Soderman, 2004; Maguire and Ojiako, 2008; Zeidler et al., 2008). This is a problem, both within the company, but also in relation to its suppliers (Matson and Matson, 2007). It can be difficult to have a shared understanding over priorities, causing specifications to contain ambiguities in describing the requirements (Kerr et al., 2006; Liu et al., 2006).

\subsection{Managing requirements in Japanese automotive industry}

Strive for simplicity is a driving force behind Japanese industry. High customer focus, crossfunctional integration, and product development team proficiency have also been identified as the success factors of Japanese NPD. Also, their requirements management has developed to meet customer needs and efficiency demands simultaneously. The NPD success is seen to originate from focusing efforts on these areas (Im et al., 2003).

Toyota has been a successful company, creating quality cars, faster and with a greater profit than its competitors. It launches more new products annually than most of the competition. (e.g. Morgan \& Liker 2006). The key aspects of Toyota's NPD are seen to comprise of knowledge being shared among projects, and especially the harmony between mechanisms (Haque and James-Moore, 2004; Haque and Pawar, 2003). Key factors of Toyota's NPD system include knowledge management, setbased concurrent engineering, and delayed decision-making (see, e.g. Morgan and Liker, 2006; Liker, 2004; Sobek et al., 1999; Hines et al., 2006; Kamath and Liker, 1994; Ward et al., 1995; Ford and Sobek, 2005). Also, Meijboom et al., (2007) have noted how platform architectures and delayed decision making aid in managing customer requirements in modern industries.

Morgan and Liker (2006) divide Toyota's PD system into three subsystems: 1) Process, 2) People, and 3) Tools \& technology, which are seen to be interdependent (see Figure 3). Processes sub-system includes defining the factors creating value to customers, whilst everything else is eliminated as waste. People sub-system is characterised by a matrix organisation, with an emphasis on functional dimension, including appointing experienced senior engineers, chief engineers (CE), into coordinating roles. Tools \& technology sub-system includes a penetrating fit-for-purpose mentality, where technologies must support people and processes, and act as means for efficiency. This threestage socio-technical model is the basis utilised for further analyses in this study. 


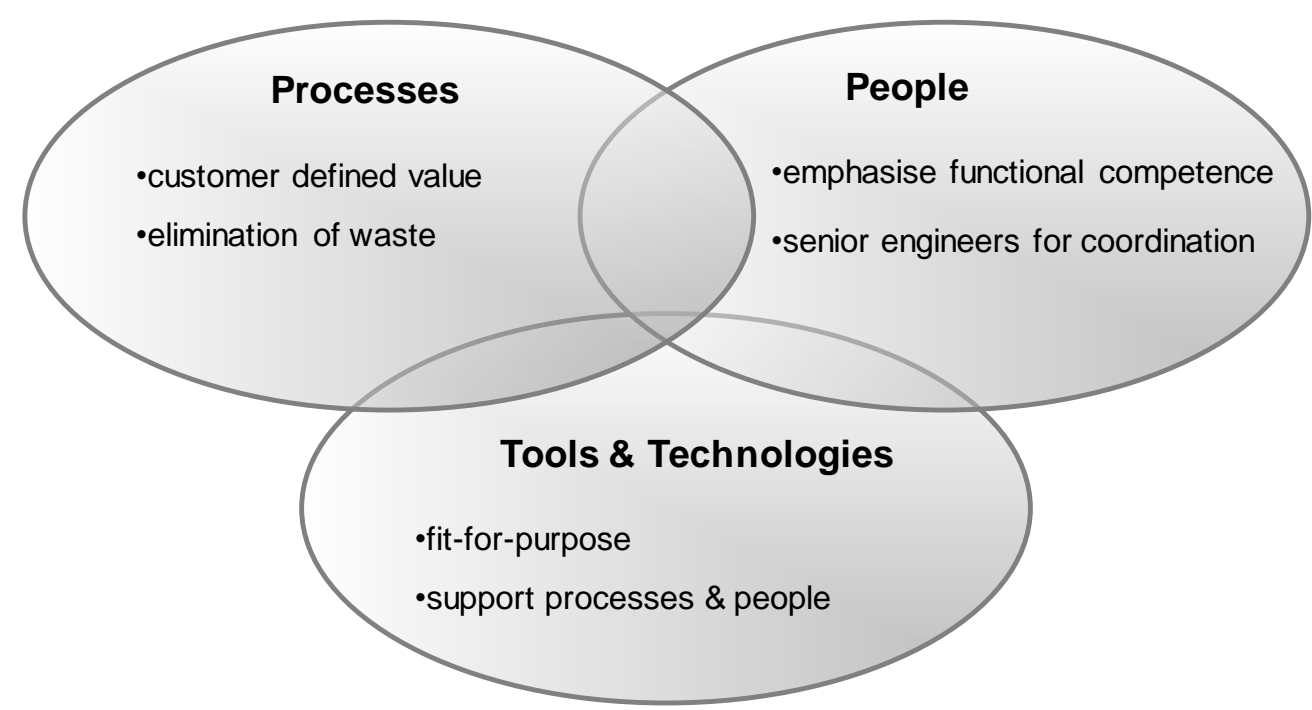

Figure 3. Three interrelated aspects of the benchmarked NPD model

\section{Empirical study}

\subsection{The research process}

The research process is described in Figure 4. First, a literature review was conducted on requirements management in order to create a solid theoretical base. The three-stage socio technical model introduced by Morgan and Liker (2006) was chosen as a benchmark to find potential development ideas for the ICT companies, for their requirements management. Interview questionnaire was then formulated (see Appendix A), and interviews were conducted, to obtain understanding on the requirements management practices in ICT companies. The interview results were first carefully analysed through considering organisational, product development, requirements management, and outsourcing aspects to enable a comprehensive understanding over the practices of the interviewed companies. The main analysis includes all the individual interviews being scrutinised separately by using the three-stage socio-technical model as the analysis tool. The comments made by the interviewees during each interview were categorised into processes, people, and tools \& technology according to the benchmark model, and the compliance/ non-compliance with the model was assessed (see Appendix B). Finally conclusions were drawn.

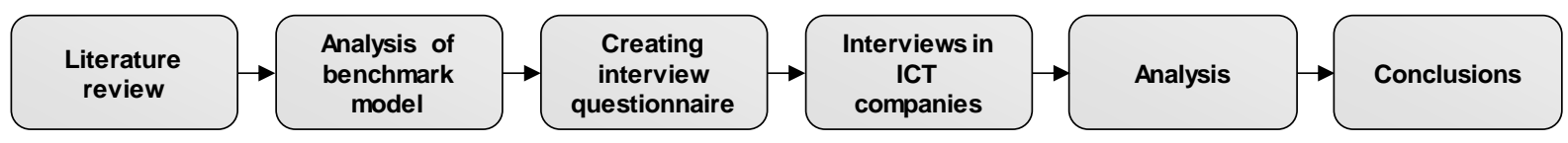

Figure 4. The research process

The research utilised a semi-structured thematic interview approach (see e.g. Merton et al., 1990). The study consisted of 45 interviews, and 12 companies, in which minimum of three people were interviewed in each. During the process, one ICT company was identified as the most advanced in requirements management, in which twelve interviews were conducted. Interviews were conducted informally, in a qualitative manner, allowing the interviewees to explain and clarify the cases and topics as entities. All the interviews were transcribed for the purpose of analysis. 
The companies that participated provide products for both business-to-customer and for business-tobusiness markets. The study covers different actors within their supply chain. Three of the interviewed companies are large significant ICT actors. The others include smaller companies with their own products and suppliers providing services/products to the larger ones. The participants interviewed were selected carefully on the basis of their professional background and expertise. The experience and the current interests ensured the high motivation among the participants and up-to-date knowledge with respect to the discussed topics. The selected participants are among the top-professionals in the ICT sector.

This study is qualitative in nature. Qualitative research is a research method aiming to understand studied phenomena. This means clarifying the meaning and significance of the phenomenon in question. Qualitative research typically utilises samples that are discretionary to the researcher. Objects under study may not be high in numbers, but are studied thoroughly, highlighting the quality of input material. However, the size of sample must be covering enough in relation to the type of analysis and interpretation intended (see e.g. Marshall and Rossmann, 1998; Siggelkow, 2007; Patton, 2002).

\section{2 Results and analysis}

The interview material was analysed by using the three-stage socio-technical model. The results obtained were analysed as entities, resulting in conclusions of the current state of the ICT industry, and indications on what the ICT can learn from Toyota's success in the automotive industry.

\subsubsection{Processes}

The interviewed companies clearly indicate processes being in place for serving customer needs. Particularly, companies in the business-to-business field seem to have close relationships with their customers, and their NPD is strongly customer-driven. However, the companies do not typically follow the lean principles in their process development by excluding all non-value adding activities. Only in isolated cases systematic reduction of non-value adding activities can be seen. In addition, employees in many of the interviewed companies seem to assume that it is only for the higher level managers to analyse customer-value and commence related actions.

All the interviewed companies indicate aims, and actions, for putting emphasis on the early stages of the NPD process. The product development in the interviewed companies is clearly platform-based, aiming towards common solutions. The biggest challenge seems to be finding platforms that fulfil the needs of later NPD, and clarifying the constraints of these internal customers. This is seen to have an impact on managing requirements.

Preparation for technological uncertainties by analysing multiple alternatives is weak in most of the studied companies. The companies seem to freeze their solutions relatively early, and do not usually study parallel alternatives. Only in isolated cases, there is evidence of using Toyota's way of delaying decision-making. It is only the advanced companies who deliberately delay decision-making by parallel development.

According to the interviews, companies seem to be insufficient in removing overlapping work. This seems to be particularly true for testing and other separate functions. Concrete actions for optimising testing seem to be unsystematic. Companies do, however, utilise fault statistics for improving their processes.

There are clear aims for standardising technical solutions and technologies in the interviewed companies. Product development processes, and requirements management are, however, not systematically standardised. In addition, people skill-set standardisation is not as strong in the interviewed companies as at Toyota. The interviewees seem to value personnel competences, but standardised career planning is not included in company policies. 
The interviewed companies have only meagre appreciation of internal customers. When addressing the needs of internal customers and solving compatibility problems the interviewed companies tend to emphasise the latter part of product development process. Only the most advanced follow Toyota and take these issues systematically into account already from the beginning of the NPD process. Especially, the smaller actors end up in a fire-fighting mode.

\subsubsection{People}

Toyota's chief engineer type solutions do not exist in the interviewed companies. The same functions are typically managed by product/programme managers. Nevertheless, there seem to be similarities in these roles. Noteworthy is that the interviewees do not name their product/programme managers as the system integrators for their NPD processes. Product/programme managers are viewed to have a strong marketing focus in contrast to Toyota where CEs have engineering backgrounds enabling them to cope with technical issues beside managerial duties. CEs are experienced people and are highly ranked, while product managers in the interviewed companies are usually much younger.

The study indicates that balancing functional expertise development and cross-functional integration are challenging for the companies. Requirements management, and testing, was brought up as especially demanding. In small companies, the success of product development projects seems to overrun functional expertise. In larger and more advanced companies, the arrangements seem to be closer to those of Toyota. The larger companies seem to have it easier to appreciate the functional expertise without having to individually split the experts into projects. In the studied companies, cross-functional integration is conducted, for example, by regularly organising seminars and internal meetings.

In the interviewed companies, the employees are themselves seen to master their own career development. In contrast, at Toyota, competence development, and career planning, of employees are management at the company level. In rapidly growing small companies, low ranking managers are typically promoted from the operational level based on urgent needs, and career changes are common.

In all the studied companies, attention is paid for developing technical competences as they are considered crucial for business success. However, it is typically up to individuals to take the responsibility for their technical competence development. Individuals are only rarely offered mentoring to develop their competences and are given possibilities for advancing towards higher positions.

The activities of subcontractors seem to be integrated in a shallower manner into company processes in the studied companies than in the socio-technical model. According to the interviewees, the subcontractor has quite often common data systems for information sharing with their customers. Nevertheless, outsourcing is easy only when the requirements are unambiguous. As a consequence, only the simple cases are outsourced. The communication between the companies is considered challenging. Toyota, on the other hand, addresses these problems by bringing the subcontractors, including their personnel, into the core of Toyota's processes.

In the studied companies, there are practices for continuous learning and improvement. For instance, meetings and reviews are organised after project closures, in order to identify development areas. Deep continuous improvement cannot be identified for the studied companies, in the same manner as at Toyota. Learning, in the interviewed companies, is typically based on previous experiences without in-depth root-cause analyses. Only most advanced companies aim to systematically transfer the lessons learned into their design guidelines and checklists. Transferring tacit knowledge is attempted via mentoring, and knowing people personally, however, systematic ways of this cannot be identified.

A strong strive for developing technologically advanced, high quality products, and improving through learning from previous mistakes can be identified in the studied companies. The culture in 
these companies is typically admiring technology, while the customer orientation and efficiency requirements are not as penetrating as at Toyota.

The most advanced interviewed companies have production representatives integrated into the NPD projects assuring the voice of production. However, this has not been taken to component level as at Toyota. All the interviewed companies utilise frequent milestone meetings. Nevertheless, these meetings are not fully equivalent to Toyota who has a more cross-functional emphasis with their Obeya room arrangements.

\subsubsection{Tools \& Technology}

According to the interviews, the studied companies have a tendency to over-value the meaning of technology. The largest and most advanced companies acquire technology based on real needs. The role of technologies is to optimally develop business processes and actual work of employees. The less developed companies do not consider this as a vital success factor needing significant attention. A follower strategy is applied in some cases, and the technologies used by other companies are analysed and exploited.

The study indicates that the businesses do not adequately assure that the information is in an appropriate format, timely, or its adaptation to different users is properly considered. There seems to be an excess of data, but it is not sufficiently processed. The companies have not recognised the need for simple visual communication, nor have a culture of broad discussions aiming for consensus. Managers feel that making decisions is a part of their role, and that there is no need for broad discussions.

The majority of the studied companies, especially the larger ones, use databases for developing processes and products. One of the greatest challenges is the amount of information, and the success rate of its utilisation varies between companies. Categorisation of the information based on its relevance is not properly addressed. The need for further processing of the collected information is comprehended well, but proper solutions have not been developed. There are, however, examples of more concrete data utilisation, such as giving feedback for engineers on the amount of defects in products in the field.

The interviewed companies utilise guidelines and checklists, but their NPD is not organised as strongly through checklists as at Toyota. Checklists are also updated more effectively at Toyota. Especially the larger companies utilise specific data bases as engineering tools for requirements management. However, the utilisation of these data bases is somewhat immature. In practice, communication in ICT often occurs via e-mail and project meetings, even though different data-bases and tools have been introduced. Traceability of requirements in the utilised data-bases is lacking due to insufficient compatibility among different tools.

\subsection{Results summary}

Product development processes and requirements management of ICT companies are analysed in this study, by using the three-stage socio-technical model as the benchmark. The motivation is to find potential development ideas for the ICT companies, for their requirements management. The study covers different actors within their supply chain.

The interviewed companies consider requirements management to contain an increasing amount of challenges. The products are getting more complicated, and there are an increasing number of actors and standards to cope with, yet everything must function flawlessly together in the end-product. According to the interviewees, the companies are hoping for simple solutions for handling this complex and conflicting set of demands. 
The study indicates how the interviewed ICT companies have an obvious aim to shift the emphasis of their product development processes towards earlier phases, the same way as highlighted in the reference model. The emphasis shift is currently complicated by the fact internal customer needs are mainly addressed towards the end of NPD process. There is a strive for finding solutions for managing the requirements during NPD, as this is considered as one of the major disturbing factors. Especially platform-based product development is seen to support the shift towards earlier phases, and also to ease the challenges of requirements management. The strategy of developing several alternatives, and technologies, is not, however, applied widely. In contrast, technological solutions are typically frozen, as early as possible, in the studied companies. The study did not find evidence on any real ambitions for the companies to systematically reduce overlapping work and all non-value adding activities.

The importance of employees' competencies and the necessity for developing them are well understood in the interviewed companies. There seem to, however, be major differences in developing competencies, among the interviewed companies and Toyota. The development of employees' competencies is strongly managed by the company at Toyota, where careers are well-planned. The studied companies seem to be missing organisation led, systematic career path planning for developing competences of the personnel. Nevertheless, there is some evidence of organised job rotation and mentoring, but for key employees only. The competence development in the interviewed companies is typically the responsibility of individual employees.

Chief engineer type solutions for managing the entire development process, and requirements, are non-existent in the studied ICT companies. Programme manager type arrangements are in use in the studied companies for the integration of development processes. Toyota has taken cross-functional integration further than the studied companies by their meeting arrangements and by assigning responsibilities to component level to assure communication from production to NPD. The companies are lacking behind Toyota, both in addressing customer requirements and in appreciating technical competences.

The interviewees indicated the processing of data gathered from products, and from customers being another challenge. There is not sufficient enough consideration of what kind of information is required by different employees at different levels. Additionally, visualisation of the most vital information is almost non-existent. These deficiencies make it difficult to follow-up and process the requirements.

Table 1 summarises the main challenges of managing requirements in the ICT sector and potential solutions to be considered from the car industry, identified in this study. 
Table 1. Challenges and potential solutions for managing requirements in the ICT sector

\begin{tabular}{ll}
\hline \multicolumn{1}{c}{ Challenges } & \multicolumn{1}{c}{ Potential learnings from Toyota } \\
\hline $\begin{array}{l}\text { Customer needs are addressed } \\
\text { inadequately }\end{array}$ & $\begin{array}{l}\text { Experienced technical people to co-ordinate } \\
\text { requirements management } \\
\text { Company driven career planning to assure required } \\
\text { skills }\end{array}$ \\
$\begin{array}{ll}\text { Internal customer needs are } \\
\text { addressed inadequately }\end{array}$ & $\begin{array}{l}\text { Better cross-functional integration } \\
\text { Obeya type meetings }\end{array}$ \\
& Assigned responsibilities \\
Requirements change during NPD & $\begin{array}{l}\text { Delayed decision making by developing parallel } \\
\text { alternatives }\end{array}$ \\
& $\begin{array}{l}\text { Gain deeper understanding, during early NPD, to } \\
\text { prepare for changes }\end{array}$ \\
Prioritising conflicting requirements & Chief engineer \\
Complex multi-site organisation & Not directly obtainable from the Toyota model \\
& \\
Overflow of data on products and & Fit-for-purpose information \\
customers & Standardised company-wide tools \\
requirements with suppliers & Simple visual communication \\
\hline
\end{tabular}

The Toyota NPD model has a lot to give to the interviewed ICT companies. However, the model does not give direct solutions to all the challenges encountered by the interviews. These challenges include, rapid market and technology changes in the ICT business and multi-project/ multi-site/ multi-culture NPD environment typical for the larger interviewed companies. In addition, the Toyota model does not give comprehensive solutions for tackling the challenges caused by contradicting requirements.

\section{Conclusions}

In this study, the main requirements management challenges of ICT companies are indentified. The challenges indentified in this study are in line with previous several earlier studies e.g. Damian and Zowghi (2003), Birk and Heller (2007) and Jiao and Chen (2006). However, this research highlighted the importance of addressing the needs of internal stakeholders and problems encountered with data overflow. This paper aims to analyse the extent the principles of Japanese car industry are used in ICT companies for tackling similar challenges, and to find potential solutions to these challenges.

The results of the empirical study indicate the largest, and more advanced, companies applying similar principles to the benchmarked model, more than their subcontractors, and the smaller companies in general. Nonetheless, all the interviewed companies utilise at least some similar principles.

In Japanese automotive industry, experienced, technical people are utilised to coordinate customer requirements throughout the entire development process. The studied companies use less experienced, younger managers for similar roles. The challenges caused by changing requirements within ICT could be considered to be tackled by using a Japanese approach of delaying decision making until sufficient amount of information is available. Developing parallel options is a way to gain deeper understanding while delaying final decisions. The problem of data overflow can be addressed through improved attention on processing the data using a fit-for-purpose mentality to tailor for different users. Japanese aim to integrate suppliers, and their personnel, fully to make communication of requirements 
more fluent. The appreciation of internal customers requires further attention in the ICT companies. Toyota gives good ideas for addressing production requirements already during early NPD.

The managers in the ICT sector should pay more attention on their requirements management as its successful organisation is an acute challenge. Requirements management, however, is not ICT specific function, and therefore, benchmarking other sectors is worthwhile as shown by this study. The requirements management of the Japanese automotive industry is a potential source for gaining fresh ideas. They have developed methods for addressing issues, such as, managing customer needs throughout the NPD process, overflow of data, and communicating requirements with suppliers.

Although NPD of the Japanese car industry is very functional for them, it is unrealistic for companies to start following their model strictly. For example, the Toyota model is not a straightforward action plan, making it challenging to apply (Rosemann, 2006). In addition, the automotive and ICT sectors are different in terms of profit margins and development timeframes. As a consequence the Toyota model can only be used as a source for development ideas in ICT companies, and the practical realisation must be conducted based on the company's realities.

This research is qualitative by nature, and its purpose is to find ideas for ICT companies for developing their NPD and requirements management practices. The intention is not to make an allinclusive analysis. Although, the participating companies are analysed by interviewing several people per company, conducting a more comprehensive analysis might give slightly different results.

Deeper analysis on more specific areas, such as the use of different data-bases, how the responsibilities of Japanese CE are covered in the ICT sector, might be interesting topics for ICT to study further. As the Toyota model does not adequately provide solutions for all the challenges in the ICT industry identified in this study, other sources for ideas can prove beneficial. This paper analyses ICT, utilising automotive industry as a benchmark, thus the number of sectors could be increased to gain a wider perspective. As the study was qualitative in nature, a quantitative study could provide new insights.

\section{Acknowledgements}

This research has been supported by Nokia Foundation, Jenni and Antti Wihuri Foundation, Tauno Tonning Foundation and Riitta and Jorma Takanen Foundation.

\section{References}

Andersson, C. and Runeson, P. (2002) "Verification and validation in industry - a qualitative survey on the state of practice", Empirical Software Engineering, Proceedings, IEEE, International Symposium.

Belt, P., Harkonen, J., Mottonen, M., Kess, P. and Haapasalo, H. (2008) "Improving the efficiency of verification and validation", International Journal of Services and Standards, Vol. 4, No. 2, pp. $150-166$.

Birk A. and Heller G. (2007) 'Challenges for Requirements Engineering and Management in Software Product Line Development'. Requirements Engineering: Foundation for Software Quality, vol. 4542, pp. 300-305.

Briand, L.C., Labiche, Y., O’Sullivan, L. and Sówka, M.M. (2006) "Automated impact analysis of UML models", Journal of Systems and Software, Vol. 79, No. 3, pp. 339-352.

Caputo, A.C. and Pelagagge, P.M. (2008) "Effects of product design on assembly lines performances: a concurrent engineering approach," Industrial Management \& Data Systems, Vol. 108, No.6, pp.726-749.

Cheng B.H.C. and Atlee J.M. (2007) 'Research Directions in Requirements Engineering'. Future of Software Engineering (FOSE'07), pp. 285-303.

Damian D.E. and Zowghi D. (2003) 'Requirements engineering challenges in multi-site software development organisations'. Requirements Engineering Journal, vol. 8, no. 3, pp. 149-160. 
Darabi, H., Chiu, J., Khorram, S., Hea J.K., Zhimin Z. Hung-Ming C., Ibrahim, B., Geronaga, E., Tran, L.H. and Rofougaran, A. (2005) 'A dual-mode $802.11 \mathrm{~b} / \mathrm{bluetooth}$ radio in $0.35-/ \mathrm{spl} \mathrm{mu} / \mathrm{m}$ CMOS', IEEE Journal of Solid-State Circuits, Vol. 40, No. 3, pp. 698- 706.

Dorfman, M. and Thayer, R. (1997) 'Software Engineering, IEEE Computer Society Press, Los Alamitos, CA, pp. 80.

Ebert, C. (2007) 'The impacts of software product management', Journal of Systems and Software, Vol. 80, No. 6, pp. 850-861.

Engel, M. and Last, M. (2007) 'Modeling software testing costs and risks using fuzzy logic paradigm', The Journal of Systems \& Software, 20079 (3), pp. 259-280.

Engelbrektsson, P. and Soderman, M. (2004) 'The use and perception of methods and product representations in product development: A survey of Swedish industry', Journal of Engineering Design, Vol. 15, No. 2, pp. 141 - 154.

Ford, D.N. and Sobek, D.K. II (2005) 'Adapting real options to new product development by modeling the second Toyota paradox', IEEE Transactions on Engineering Management, Vol. 52, No. 2, pp. $175-185$.

Fricker, S., Glinz, M. and Kolb, P. (2006) 'A Case Study on Overcoming the Requirements Tar Pit', Journal of Universal Knowledge Management, vol. 1, no. 2, pp. 85-98.

Gilb, T. (2005) 'Competitive Engineering: A Handbook for Systems Engineering, Requirements Engineering, and Software Engineering Using Planguage', pp.480.

Gupta, A., Pawara, K.S. and Smart, P. (2007) 'New product development in the pharmaceutical and telecommunication industries: A comparative study', International Journal of Production Economics, Vol. 106, No. 1, pp. 41-60.

Haque, B. and James-Moore, M. (2004) 'Applying lean thinking to new product introduction', Journal of Engineering Design, Vol. 15, No. 1, pp. 1-31.

Haque, B. and Pawar, K.S. (2003) "Organisational analysis: A process-based model for concurrent engineering environments", Business Process Management Journal, Vol. 9, No. 4, pp. 490-526.

Hines, P., Francis, M. and Found, P. (2006) 'Towards lean product lifecycle management: A framework for new product development," Journal of Manufacturing Technology Management, Vol. 17, No.7, pp. 866-887.

Im, S.,Nakata, C., Park, H. and Ha, Y.W. (2003) "Determinants of Korean and Japanese New Product Performance: An Inter-Relational and Process View," Journal of International Marketing, Vol. 11, No. 4, pp. 81-112.

INCOSE (2008) 'INCOSE Requirements Management Tools Survey', the International Council on Systems Engineering, [www-document] <http://www.paper-review.com/tools/rms/read.php> Read 20.05.2008.

Jiang, L., Eberlein, A. and Far, B.H. (2008) "A case study validation of a knowledge-based approach for the selection of requirements engineering techniques", Requirements Engineering, Vol. 13, No. 2, pp. 117-146.

Jiao J. and Chen C.H. (2006) 'Customer requirement management in product development: a review of research issues'. Concurrent Engineering; research and Applications, Vol 14, No. 3, pp. 173185.

Kamara, J.M., Anumba, C.J. and Evbuomwan, N.F.O. (2000) "Process model for client requirements processing in construction", Business Process Management Journal, Vol. 6, No. 3, pp. 251-279.

Kamath, R. and Liker, J. (1994), 'A second look at Japanese product development', Harvard Business Review, Vol.72, No. 6, pp. 154-170.

Kauppinen M., Vartiainen M., Kontio J., Kujala S. and Sulonen R. (2004) 'Implementing requirements engineering processes throughout organizations: success factors and challenges'. Information and Software Technology, 46. pp 937-953.

Kerr, C.I.V., Roy, R. and Sackett, P.J. (2006) 'Requirements management: an enabler for concurrent engineering in the automotive industry ', International Journal of Production Research, Vol. 44, No. 9, pp. 1703 - 1717. 
Kim, J., Kim, J., Park, S. and Sugumaran, V. (2004) 'Title: A multi-view approach for requirements analysis using goal and scenario', Industrial Management \& Data Systems, Vol. 104, No. 9, pp. 702-711.

Kotonya G., and Sommerville I. (1998) 'Requirements Engineering: Processes and Techniques', Wiley, England, 294 p.

Larsen, T.J., Niederman, F., Limayem, M. and Chan, J. (2008) 'The role of modelling in achieving information systems success: UML to the rescue?', Information Systems Journal, Fortcoming

Lauesen S. (2002) 'Software requirements - Styles and techniques', Addison-Wesley,

Harlow, $591 \mathrm{p}$.

Liker, J. (2004) 'Toyota Way', McGraw-Hill, pp.330.

Liu, F., Noguchi, K., Dhungana, A., Srirangam A.V.V.N.S.N. and Inuganti, P. (2006) 'A quantitative approach for setting technical targets based on impact analysis in software quality function deployment (SQFD), Software Quality Journal, Vol. 14, No. 2, pp. 113-134.

Maguire, S. And Ojiako, U. (2008) "Market-led systems development: when customers become users," Industrial Management \& Data Systems, Vol. 108, N2, pp.173-190.

Marshall, C. and Rossman, G.B. (1998) 'Designing Qualitative Research', 3rd edition, Thousand Oaks, Sage Publications, p.240.

Matson, J.E. and Matson, J.O. (2007) 'Just-in-time implementation issues among automotive suppliers in the southern USA', Supply Chain Management: An International Journal, Vol. 12, No. 6, pp. 432-443.

Meijboom, B., Voordijk, H. and Akkermans, H. (2007) 'The effect of industry clockspeed on supply chain co-ordination: Classical theory to sharpen an emerging concept', Business Process Management Journal, Vol. 13, No. 4, pp. 553-571.

Merton, R., Fiske, M. and Kendall, P. (1990) 'The Focused Interview: A Manual of Problems and Procedures', 2nd ed. New York: The Free Press.

Misra, S.C., Kumar, U. and Kumar, V. (2008) 'Modelling strategic actor relationships for risk management in organizations undergoing business process reengineering due to information systems adoption', Business Process Management Journal, Vol. 14, No. 1, pp. 65-84.

Morgan, J.M. and Liker, J.K. (2006) 'The Toyota product development system: integrating people, process, and technology', pp. 377.

Nonaka, I., Takeuchi, H. and Takeuchi, H. (1995) 'The Knowledge-creating Company: How Japanese Companies Create the Dynamics of Innovation', Oxford University Press, pp. 284.

Oberg R., Probasco L., and Ericsson M. (1998) 'Applying requirements management with use cases', Rational Software Corporation, pp. 21.

Patton, M.Q. (2002) 'Qualitative Research and Evaluation Methods', 3rd edition, Thousand Oaks, Sage Publications, p.598.

Perttula, A. (2007) 'Challenges and Improvements of Verification and Validation Activities in High Volume Electronics Product Development', PhD dissertation, Tampere University of Technology, Finland. Publication 650

Pisano, G.P. and Wheelwright, S.C. (1995) 'The new logic of high-tech R\&D', Harvard Business Review, Vol. 73, No. 5, pp. 93-104.

Rosemann, M. (2006) 'Potential pitfalls of process modeling: part B', Business Process Management Journal, Vol. 12, No. 3, pp. 377-384.

Rui, M., Yang, J., Hutchinson, J. and Wang, J. (2008) 'Managing knowledge for new product performance in the high technology industry', International Journal of Technology Management, Vol. 41, No. 1-2, pp. 96 - 108.

Siggelkow, N. (2007) 'Persuasion with case studies', Academy of Management Journal, Vol. 50, No. 1, pp. 20-24.

Sobek, D., Ward, A. and Liker, J. (1999), 'Toyota's principles of set-based concurrent engineering', Sloan Management Review, Vol. 40, No. 2, pp. 67-83.

Sommerville I. (2004) 'Software engineering', 7th edition, Addison-Wesley, Essex, England, 759 p. 
Thayer, R. and Thayer, M. (1997) 'Software Requirements Engineering Glossary', in: R. Thayer, M. Dorfman (Eds.), Software Requirements Engineering, Second ed., IEEE Computer Society Press, Los Alamitos, CA, USA, pp. 489-528.

Ulrich, K.T. and Eppinger, S.D. (1995) 'Product Design and Development', McGraw-Hill, New York, pp. 320.

Ward, A., Liker, J., Cristano, J. and Sobek, D. (1995), 'Second Toyota paradox: how delaying decisions can make better cars faster”, Sloan Management Review, Vol. 36, No. 3, pp. 43-61.

Weber, M. and Weisbrod, J. (2003) 'Requirements engineering in automotive development: Experiences and challenges', IEEE Software, Vol. 20, No. 1, pp. 16-24.

Wheelwright, S.C. and Clark, K.B. (1994) 'Accelerating the Design-build-test Cycle for Effective Product Development", International Marketing Review, Vol. 11, No. 1, pp. 32-46.

Zeidler, C., Kittl, C. and Petrovic, O. (2008) 'An integrated product development process for mobile software', International Journal of Mobile Communications, Vol. 6, No. 3, pp. 345 - 356.

Zhang, A. (2008) "Examining product and process effects on consumer preferences from online and offline channels," Business Process Management Journal, Vol.14, No.1, pp.85-95. 


\section{Appendix A}

\section{Background information}

- Name of the interviewee

- Title

- Start date in the current role

- Previous experience

- Company

- Site

- Company's products

- Number of employees in product development

\section{Organisational practices}

2.1 What type of organisational structures are utilised in your company?

a. How has this developed in the past?

b. What types of factors have influenced this?

c. How is the customer viewpoint taken into account in your organisational structure?

d. Which other viewpoints (apart from customer) does your organisation support? (Product, knowhow, etc.)

2.2 Do the employees typically have more than one boss?

a. If so, how do you manage this successfully?

2.3 What are the main success factors for your company?

2.4 Have you defined the core know-how for your company?

b. If so, what are the main know-how in your company?

2.5 How else, apart from the organisational structure, does your company assure the customer orientation in your company?

a. How has this been realised in your product development?

2.6 Who are the key people in your company?

a. How do you level the workload among your employees?

b. Do you have a reward system in place for your employees?

\section{Outsourcing}

3.1 Have you outsourced any functions in your company? Which?

a. Who are responsible of these functions?

b. Do you use any meters for the performance of the outsourced functions, if so what type?

c. How do you manage the information flow between you and your suppliers (formal, informal, meetings, reporting, databases, ...)?

3.2 Do you have intentions of increasing/ decreasing the number of suppliers?

3.3 What are the organisational challenges in outsourcing in your company?

\section{Product development}

4.1 Which phase of the NPD chain do you represent?

4.2 What do you expect of the previous NPD phase?

4.3 What types of problems created in the previous phase/s arise here?

4.4 What type of actions in this phase could serve the following phase/s the best?

4.5 How do you organise for rapid product development (Time-to-market)?

a. How do you take TTM into account in your organisation / operations?

4.6 What are your core technical know-how?

a. How do you assure the development of this know-how?

b. Should the experts be divided into projects, how do you assure the development and the level of the core know-how? How do the experts communicate among each other? 
c. Should you organise into functional expert teams, how do you assure an effective customer / product orientation?

4.7 Timing of decisions in product development

a. At what stage do you decide technologies to be used in the product, and freeze the development?

b. Do you develop several alternatives simultaneously, or take a single concept from start to launch?

c. Do you use platforms -> if so, to what extent?

4.8 Do you aim to standardise technological solutions (other than using platforms) - how?

4.9 Which factors influence the decisions when considering technologies that support your NPD?

4.10 Is agility relevant for your company - How?

4.11 Are lean practices relevant for your company - How?

4.12 What are the main principles in your company for developing NPD activities?

\section{Requirements, Managerial perspective}

5.1 What type of activities do you consider as requirements management?

5.2 Describe typical requirements management activities within the NPD phase you represent?

5.3 How can the requirements management activities be improved, in your view?

5.4 Are there any bottlenecks you have identified?

5.5 Do you know the share of resources spent on requirements management?

a. Can you describe it in numbers?

b. Do you measure these costs - how?

c. Are these expenses increasing / decreasing in relation to your turnover?

5.6 How have you organised requirements management? Separate unit? Other?

a. What kind of decision making mechanism do you have these issues?

b. How do you organise the development / rationalisation of these activities?

5.7 If you have separate departments for technologies (SW, HW, ASIC, etc.), how do you manage the whole?

5.8 How do you take the customer needs and requirements into account? Validation?

a. Who is responsible?

5.9 Do you have measures / indicators for the effectiveness of requirements management? - Please define?

a. Are the effectiveness indicators connected to financial information?

5.10 How does standardisation influence your operations?

5.11 Does the customer test your product? If so, what type of feedback is given?

\section{Other comments}

Do you have any other comments relating to the discussed topic?

(The details of the interviewee, or the company, will not be disclosed in any published material.) 


\section{APPENDIX B}

\section{Processes}

$+=$ Compliance; $-=$ non-compliance; $0=$ issue/challenge identified, but not properly addressed

Examples of interviewee comments

+ "Customer needs are taken into account when defining the requirements. However, we tend to be keen-eared for possible changes also later. All the activities must be in sync, including marketing, sales, logistics and suppliers."

+ "The key clients' will define the direction of developing products, and for the required tests."

+ "Product oriented operations means that in practice we aim at minimising all the activities not directly leading to productisation."

+ "Customer satisfaction is monitored constantly, and it does have a direct effect to individual salaries."

+ "Early product development provides a correct platform and mature enough technologies for different uses."

+ "Evolutionary platform development enables rapid product development, and is similar to connecting Lego blocks."

+ "Platforms are developed to be generic, and are configured on product basis when required."

+ "Developing platforms and modules serves the company's own R\&D, in the form of not having to dissect and test the same subjects multiple times."

+ "The workload of our employees is monitored frequently."

+ "The information on test results and repair actions is utilised to improve the process."

+ "Steering group follows the project statuses and resource needs. Resources are moved between projects based on the competences of our employees. The key people have back up persons."

+ "Product development is speeded up by effective working, right type of organisation, adequate recourses and quality work. Tasks must be clear enough for the employees to know what to do. We use milestones in our product development."

+ "Classifying errors based on their severity is of significant importance. This helps to understand how to develop test environments, and how to manage requirements better."

+ "Our products are modular, for which defining the interfaces precisely are of critical importance."

+ "We try not to end up in a situation where someone is irreplaceable, we purposely build overlapping know-how. However, an individual employee leaving the company usually causes some temporary hassle."

+ "By developing standard interfaces between tools and software, the same tests could become more universal."

+ "We aim to standardise especially hardware interfaces. Software interfaces are standardised so that everyone would use the same."

+ "Our DfX practices have improved communicating requirements between manufacturing and product development."

0 "Product development should be as close to the customer as possible, with minimum documentation."

0 "Ideally, early product development provides the correct components that have already been sufficiently tested and are ready to be used."

0 "It is important to consider appropriately already in the early phases of product development what the requirements are, and what should be tested and how."

0 "A challenge is to avoid concentrating too much on ideas on the expense of considering the practicalities and on how the later development would benefit of the results the most."

0 "Planning and defining the requirements for testing is important. There is no need to repeat the same things later once the conducted tests are soundly documented."

0 "A translation of the testing activities is provided to the production. Ideally, we have verified the product adequately before production."

0 "The work is easier to complete, if it is possible to circulate the same personnel between early and late product development."

"We do not consider, separately in different stages, whether something adds value to the customer, or not, as this has been considered in the beginning."

- "The employees focus more in finding technological solutions, than aiding the later development activities and productisation."

- "Often technology is too immature for production, and issues, such as the component variation ought to be considered more, already during the product development."

- "We aim to freeze the technologies that are utilised in our products, as early as possible."

- "In early product development, there is usually deficient documentation on V\&V and e.g. no guidelines for required equipment."

- "Sometimes incomplete platforms are taken further, when their development is finished in the productisation."

- "Production would benefit of having more characteristics supporting testing, e.g. self testing features. Thus, the product development probably concentrates more on the customers' requirements."

- "Tight schedules cause prioritisation, and the internal wishes are often secondary."

- "We are not learning enough from the previous examples as the projects tend to be unique, and we are lacking of systematic processes for V\&V."

- "Other functions do not always understand our requirements well enough, so that they could accommodate for our real needs."

_ "Key personnel often end up in a double role, and under an unnecessary work burden, when they transfer to a new position in our organisation."

_ "It is a serious challenge, when the software intended for a product is still under development and a product cannot be taken to a desired state e.g. for testing." 
- "We (production) have difficulties in getting our message through to product development."

- "We get the majority of production feedback during prototyping."

- "We do not have resources to proactively tackle everything, and often use ad hoc solutions."

\section{People}

+ = Compliance; - = non-compliance; 0 = issue/challenge identified, but not properly addressed

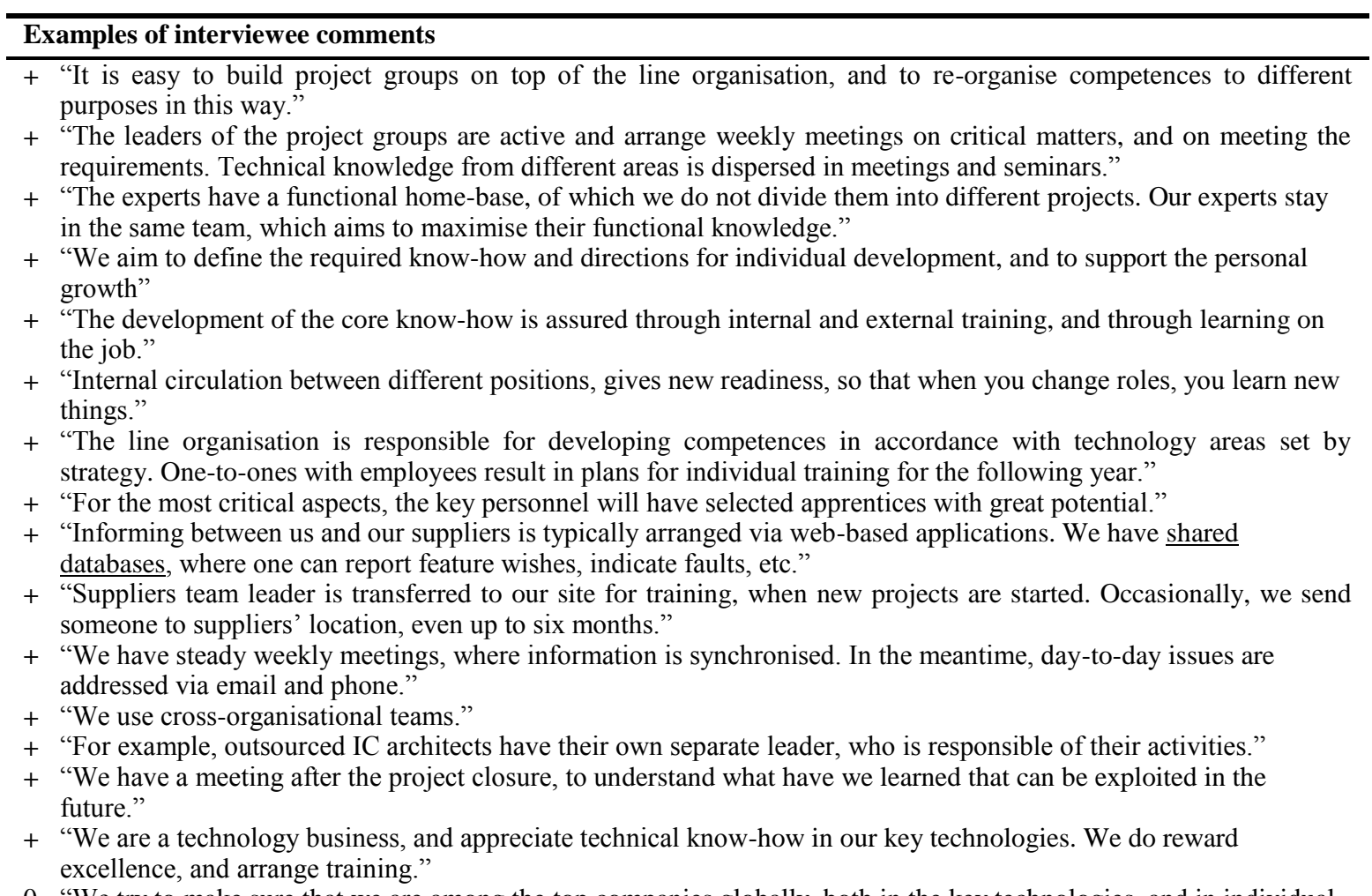

0 "We try to make sure that we are among the top companies globally, both in the key technologies, and in individual know-how."

0 "As a small supplier, we all are directly involved with our customers."

0 "Co-operation with measuring equipment manufacturers and with test software houses is important. This is to assure detailed fulfilment of the requirements set by the new products."

0 "The quality of our service is largely based on the know-how of individuals. The company invests in the individual expertise, to some degree, but it is also the responsibility of individuals."

0 "Analysing the number of faults is a part of our bonus system."

0 "We have regular milestone meetings to check the project status and to deal with problems."

_ "Customer requirements are provided by product management. Product development's task is to realise these requirements, not to come up with their own."

"The largest customers have key account managers, who take care of the customer interface on full time basis."

- cCustomer-oriented product development is assured by the steering group setting the product development projects, sales and marketing have strong representation in this. Marketing's product managers also guide the realisation of product development projects."

- "Due to schedules and pressures to be profitable, we concentrate on keeping to the project schedules, and on successful completion."

"The development of know-how is supported, but is dependent on the initiatives of each individual."

- "Receiving information from the suppliers is especially tricky as the feedback loop is not always effective enough."

- "It is the key account manager's who take care of the customer interface, and mainly negotiate our deals.

- "We are now able to go to any vendor and tell them that we want XXXX A, B, and C, and for what cost."

- "The greatest part of development is through daily work, or on employees own time. Unfortunately, once you are at a certain level of expertise, the company is unable to provide training in-house."

- "I would assume that our product development has been thought through at a higher level, so that it will be as rapid as possible."

- "The bottom line is that the team members are the best experts in their field, and therefore we do not tell them how to do things. The only limitations are for finding the solutions, the set schedules, set resources, and realisation with particular components."

"Participation of sales and production personnel in our milestone meetings is not adequate." 


\section{Tools \& Technology}

+ = Compliance; - = non-compliance; 0 = issue/challenge identified, but not properly addressed

Examples of interviewee comments

+ +"We do not use the existing software tools, but code our own that will better fit our needs."

+ "When possible, we use automated tools for testing software, as manual testing is experienced slow and boring."

+ "Faults are logged into the fault database, and are directed to the original developer, whom will receive personal feedback in this way."

+ "For example, all the materials and the related test data are recorded."

+ "The customer feedback, test results and any repair actions are recorded and collected into different type of electric databases. This data can later be utilised for improving the processes, new products and even subcontractors' activities."

+ "We have just launched a change milestone characteristic in our database, to allow adding new features easily. It is vital to be able to make last minute changes."

+ "DOORS $\AA$ is used as the main engineering tool for communicating requirement"

0 "It is decisive to be able to receive timely information over the most critical characteristics of the product from the product development activities."

0 "Sufficiently arranged electric communication is essential for communicating relevant requirements and V\&V related issues, especially if operations are decentralised"

0 "Planning the V\&V activities, and having meaningful requirements to be verified, is of utmost importance as once all this is proficiently documented, there is no need to verify something in late product development, should the very same already be done before."

_ ' "It would be ideal, if we had the capacity to sufficiently analyse our needs, when considering procuring technology.

In practice, we rarely have resources for this"

- "Acquiring technology is guided by our need to be at the pinnacle of development."

- "We usually follow which tools the others in the field are using."

- "The requirements information from different phases should be looped back more visibly."

_ "Any recorded information on requirements should be better available."

_ "Better visibility over the true context of requirements and V\&V activities in other NPD phases could potentially raise the value of any given piece of information."

- "The speed of receiving any error indications is as an area of improvement, so that the testing activities can react quicker to any arising issues."

_ "The large amount of collected data is a possible source of confusion. More effective ways of managing the collected data into a form that is both useful and unambiguous enough are desirable."

_ "The systems utilised for managing the requirements and test data are often too fragmented. This challenge is an area of current improvement actions."

- "In an ideal situation, every single phase would complete a report over V\&V activities, carefully describing everything essential. Unfortunately, this is not a possible practice."

"We do use guidelines and checklists, but quite often designers complain that they are out of date." 